Federal Reserve Bank of Minneapolis

Putting Home Economics

Into Macroeconomics (p. 2)

Jeremy Greenwood

Richard Rogerson

Randall Wright

The Macroeconomic Effects of World Trade

in Financial Assets (p. 12)

Harold L. Cole 
Federal Reserve Bank of Minneapolis

\section{Quarterly Review vol. 17, No.3}

ISSN 0271-5287

This publication primarily presents economic research aimed at improving policymaking by the Federal Reserve System and other governmental authorities.

Any views expressed herein are those of the authors and not necessarily those of the Federal Reserve Bank of Minneapolis or the Federal Reserve System.

Editor: Arthur J. Rolnick

Associate Editors: S. Rao Aiyagari, John H. Boyd, Warren E. Weber Economic Advisory Board: Edward J. Green, Ellen R. McGrattan, Neil Wallace Managing Editor: Kathleen S. Rolfe

Article Editor/Writers: Kathleen S. Rolfe, Martha L. Starr

Designer: Phil Swenson

Associate Designer: Beth Leigh Grorud

Typesetters: Jody Fahland, Correan M. Hanover

Circulation Assistant: Cheryl Vukelich

The Quarterly Review is published by the Research Department of the Federal Reserve Bank of Minneapolis. Subscriptions are available free of charge.

Articles may be reprinted if the reprint fully credits the sourcethe Minneapolis Federal Reserve Bank as well as the Quarterly Review. Please include with the reprinted article some version of the standard Federal Reserve disclaimer and send the Minneapolis Fed Research Department a copy of the reprint.
Direct all comments and questions to

Quarterly Review

Research Department

Federal Reserve Bank of Minneapolis P.O. Box 291

Minneapolis, Minnesota 55480-0291

(612-340-2341 / FAX 612-340-2366). 


\title{
The Macroeconomic Effects of World Trade in Financial Assets*
}

\author{
Harold L. Cole \\ Economist \\ Research Department \\ Federal Reserve Bank of Minneapolis
}

Unlike the United States, which has placed very few restrictions on the ability of domestic residents to invest abroad or foreigners to invest domestically, most countries have in the past chosen to substantially restrict international capital flows. Recently, though, there has been movement toward more open financial markets. The international component of this recent liberalization of financial markets has included reduced restrictions not only on borrowing and lending internationally, but also on the trade of more sophisticated assets, such as stocks, and the holding of deposits denominated in foreign currencies. The extensive international portfolio diversification which more integrated international financial markets would allow has not as yet materialized (French and Poterba 1991, Tesar and Werner 1992). However, since such a diversification would enable countries to mitigate the risk associated with fluctuations in domestic output by reducing their impact on domestic wealth and thus raise welfare, the degree of international diversification is likely to increase in the near future as transaction costs decline and information about the various opportunities becomes more widespread. (See Svensson 1988 for a discussion of the motivations for trade in risky assets.)

As world financial markets become more integrated and people more internationally diversified and hence more insulated from domestic economic shocks, they are at the same time more exposed to foreign shocks. As a result, the extent to which events in foreign countries, such as the recent decline in the Tokyo stock market, affect the United States and other economies will probably increase. This may substantially alter the response of a country's economy to normal business cycle shocks. Economists have not as yet developed models which can provide much insight as to the potential effects of an increase in international diversification on the volatility of key macroeconomic aggregates. This article develops a very simple model in which output fluctuations are induced by productivity shocks. I use this model to examine the likely impact of increased financial integration.

The article focuses on the impact of the increasing trade of sophisticated financial assets. With such assets, the payoff on an asset is state-dependent or -contingent; hence, these assets can induce large ex post income or wealth transfers. While such assets can be particularly effective in helping to diversify risk, they also induce an additional channel through which economic events in one country can impact on another country. Without these assets, the only channel for a country's productivity shocks to affect the agents in another country is changes in relative prices, such as the world real rate of interest. With free trade in state-contingent assets, there is an additional

*This is a revised version of a paper published in the International Economic Review (May 1988, vol. 29, no. 2, pp. 237-59): "Financial Structure and International Trade" by Harold Cole. The article appears here with the permission of the University of Pennsylvania. (C) All rights reserved. 
channel for cross-country effects of productivity shocks: the income flows associated with these assets.

In order to gauge the potential long-run impact of the recent international financial liberalization, I examine the behavior of some key macroeconomic aggregates like consumption, output, total labor effort, and the trade balance under two fairly extreme financial structures. I first consider a primitive system of intermediation that only involves financial assets which are traded only after the resolution of uncertainty and are therefore not state-contingent (ex post securities). This simple structure is included because it provides a useful benchmark and because it corresponds to the type of financial structure assumed in much of real trade theory. (See Jones and Neary 1984 for a survey of this literature.) I then consider the most sophisticated financial structure in which all conceivable financial assets can be traded. One convenient way to represent such a complete securities market is to have an asset which pays off one unit for each possible future event (socalled Arrow securities).

The greater ability to pool risk under the more sophisticated financial structure leads countries to diversify, and as a result, their wealth is less affected by fluctuations in domestic output. Yet this increased international risk-pooling also makes domestic wealth more dependent on fluctuations in foreign output. On net, the overall variability of domestic wealth falls, and this leads to a fall in the variability of domestic consumption. Since the link between a country's output and its wealth has been reduced, the covariance of domestic consumption and output decreases too, while that between domestic consumption and foreign output increases.

Another effect of the risk-pooling is an increase in the variability of labor effort if, as the evidence seems to indicate, labor effort is procyclical. Labor effort varies more because the substitution effect induced by temporarily higher real wages is no longer as dampened by the negative income effects of the increase in wealth induced by the productivity shock through higher real wages and profits.

The impact of risk-pooling on the trade balance is ambiguous. Since in this model the trade balance is equal to domestic output less domestic consumption, the increase in the variance of output and the decrease in the covariance of output with consumption tend to increase the variance of the trade balance while the decrease in the variability of consumption tends to decrease it.

The results implied by this model are fairly robust, in that they are likely to emerge in any model in which fluctuations are induced by productivity shocks. However, the results may be sensitive to the source of randomness one assumes. An alternative approach by which I could have introduced uncertainty into the model is to allow for stochastic government policies or some sort of preference shocks in the model. ${ }^{1}$

\section{The Model in General}

I have chosen to consider the simplest type of model that could generate the standard considerations of risk-sharing and the separation between the timing of consumption and income within an international context. (See Helpman and Razin 1978 for more elaborate models of international trade under uncertainty.) In order to be able to allow for international intertemporal trade, there are two countries and two periods in the model, but I restrict myself to only one nonstorable consumption good in each period. The agents in the model consume in both periods, but work only in the first on either of two production projects.

Project 1 produces output in the form of the first-period nonstorable consumption good immediately, while project 2 produces the consumption good only in the next period. These production projects use labor as the only input. In order to introduce a motivation for risk-sharing into the model, I assume that the outputs of these two projects are random. This randomness can be thought of as arising from exogenous shocks due to weather, technological innovation, or surprise changes in the price of unmodeled inputs. For simplicity, I assume that these productivity shocks are the same within a country on a particular type of project, but may differ across project types and countries.

The projects produce the nonstorable consumption good according to the production function $y_{j}^{i}=\theta_{j}^{i} f_{j}\left(l_{j}^{i}\right)$ for $j=1$, 2 and $i=A, B$, where $y_{j}^{i}$ denotes the output of project $j$ in country $i, l_{j}^{i}$ denotes the labor input in project $j$ in country $i$, and $\theta_{j}^{i}$ denotes the random productivity shock to project $j$ in country $i$. Let $f_{j}(\cdot)$ be such that $f_{j}^{\prime}>0$ and $f_{j}^{\prime \prime}<0$. It is assumed that the productivity shocks are independently and identically distributed elements of the finite set $\Theta$ of positive real numbers. The marginal distribution function of a country's productivity shocks, $\theta^{i}=\left(\theta_{1}^{i}, \theta_{2}^{i}\right)$ for $i=A$,

\footnotetext{
${ }^{1}$ The approach I have taken here is similar to that in the real business cycle literature which assumes there is some unmodeled source of uncertainty with regard to total factor productivity; see, for example, Kydland and Prescott 1982, Prescott 1986, or Backus, Kehoe, and Kydland, forthcoming.
} 
$B$, is given by $n\left(\theta^{i}\right)$. Less formally, the value of the $n\left(\theta_{1}^{i}, \theta_{2}^{i}\right)$ gives the probability of the realized pair of productivity shocks being $\left(\theta_{1}^{i}, \theta_{2}^{i}\right)$. $^{2}$

Because I wish to avoid distributional issues within a country, I assume that within any one country all the agents are identical. I distinguish between domestic and foreign agents' choice and state variables by the use of the superscripts $A$ and $B$, respectively. The agents are assumed to have identical preferences over first- and second-period consumption as well as first-period labor effort. The domestic and foreign agents are assumed to have identical preferences over consumption and labor effort, which are given by

$$
u\left(c_{1}^{i}, c_{2}^{i}\right)-v\left(l_{1}^{i}+l_{2}^{i}\right)
$$

for $i=A, B$, where $c_{j}^{i}$ denotes period $j$ consumption of the representative agent from country $i$. By assumption, $u(\cdot)$ is concave and homothetic, where $u_{j}>0, u_{j j}<0$ for $j=1$, $2, v^{\prime}>0$, and $v^{\prime \prime}>0$.

Empirically there are no strong results on the impact of changes in labor effort on the marginal utility of consumption or changes in the level of consumption on the marginal disutility of effort. So it is reasonable to assume that there is no effect and that preferences are separable in consumption and labor effort, though these assumptions will turn out to be important in deriving some of our results. The assumption that $u(\cdot)$ is homothetic, which means that the marginal utilities of first- and second-period consumption depend only on the ratio of first- to second-period consumption, seems intuitively appealing in that there is no strong evidence that higher or lower overall consumption has much impact on people's preferences over future as opposed to current consumption. The combined effect of these preference assumptions is to insure that the two consumption goods and leisure are all normal goods (that is, goods for which consumption increases with wealth), which seems consistent with what we observe.

For simplicity, the two representative agents are by construction identical ex ante and differ ex post only in terms of their productivity shocks. The state of the economy in terms of the endogenous variables in the model (in particular, the decisions of the agents) depends only on the vector of exogenous productivity shocks, $s=\left(\theta^{A}, \theta^{B}\right)$. Since I assume that the shocks are independent across countries, the probability of any given state is just the product of the probabilities of the associated country shocks. For nota- tional convenience, I let the marginal distribution function of the state be given by $h(s)=n\left(\theta^{A}\right) n\left(\theta^{B}\right)$.

\section{A Simple Financial Structure}

The first system of intermediation that I will analyze is one involving securities that can only be traded after the productivity shocks have already become known. In this case, there is no direct insurance role for the international financial markets to play since the shocks are known and the wealth consequences of receiving a good or bad productivity shock have already become manifest. In this restricted case, the only role for an international financial market is to reallocate wealth between the first and second period. This financial structure will enable agents to specialize in production according to their comparative advantage and to separate the timing of their consumption and output.

In this market, first-period consumption units are exchanged for promises to pay a certain number of secondperiod consumption units tomorrow. The actual security that is exchanged in this market could be either in the form of a real bond which is issued by the borrower and which promises $1+r$ units of second-period consumption for each unit of first-period consumption given up or in the form of a real IOU in which for each unit of consumption received today the individual promises to pay $p$ units of consumption next period. The ratio of the number of real consumption units that one must give up tomorrow to receive some number of units of consumption today determines simultaneously the real interest rate prevailing in the first period and the relative price of second-period consumption in terms of first. An arbitrage argument can be made which implies that this ratio must be the same regardless of how many units are exchanged by any one agent if the number of other agents is large. Given a relative price $p$ of a unit of second-period consumption in terms of first-period consumption units, the level of firstperiod saving or borrowing determines the saving level that must prevail in the second period if the agent's debt contract is not to be violated nor is wealth to be left unspent. That is,

$$
\theta_{1} f_{1}\left(l_{1}\right)-c_{1}=p\left[c_{2}-\theta_{2} f_{2}\left(l_{2}\right)\right]
$$

\footnotetext{
${ }^{2}$ Allowing for some cross-country or intertemporal correlation in the productivity shocks does not change the nature of my results. However, assuming that the shocks are perfectly correlated across countries or have a completely permanent character does substantially change the model's predictions.
} 
An equilibrium in this model is a set of first-and second-period consumptions and project 1 and 2 labor inputs for each of the two types of agents, $\left\{c_{1}^{i}, c_{2}^{i}, l_{1}^{i}, l_{2}^{i}\right\}$ for $i=A$, $B$, such that the actions that the equilibrium prescribes for any agent are individually optimal and such that the firstand second-period goods clear the market (in the sense that world supply of the consumption good is equal to world demand).

If the equilibrium prescription of an agent's actions is to be individually optimal, then it must be a solution to the choice problem that agent confronts in the model. The problem of an agent in a given country is to

$$
\text { choose }\left\{c_{1}, c_{2}, l_{1}, l_{2}\right\}
$$

so as to

$$
\text { maximize } u\left(c_{1}, c_{2}\right)-v\left(l_{1}+l_{2}\right)
$$

subject to

$$
c_{1}+p c_{2}=\theta_{1} f_{1}\left(l_{1}\right)+p \theta_{2} f_{2}\left(l_{2}\right) .
$$

The agent's first-order conditions are

$$
\begin{aligned}
& u_{1}=\lambda \\
& u_{2}=\lambda p \\
& v^{\prime}=\lambda \theta_{1} f_{1}^{\prime} \\
& v^{\prime}=\lambda p \theta_{2} f_{2}^{\prime} .
\end{aligned}
$$

From the first-order conditions (6) and (7), we get

$$
u_{2} / u_{1}=p .
$$

This is the standard optimality condition from consumer theory which requires that the marginal rate of substitution between any two goods be equal to their real relative price. The separability of consumption and labor in the agent's preferences and the homotheticity of $u(\cdot)$ imply that the marginal rate of substitution between first- and second-period consumption depends only on their ratio.

Similarly, first-order conditions (8) and (9) imply that

$$
\theta_{1} f_{1}^{\prime}\left(l_{1}\right) / \theta_{2} f_{2}^{\prime}\left(l_{2}\right)=p .
$$

What this condition says is that because of the perfect substitutability of labor between the two projects in the agent's preferences, the agent allocates labor effort so as to equate the present value of the marginal products of labor. This reflects the fact that the agents are specializing in production according to their intertemporal comparative advantage, which is dictated by different realizations of their productivity shocks.

The market-clearing conditions that must hold in equilibrium are

$$
\begin{aligned}
& c_{1}^{A}+c_{1}^{B}=\theta_{1}^{A} f_{1}\left(l_{1}^{A}\right)+\theta_{1}^{B} f_{1}\left(l_{1}^{B}\right) \\
& c_{2}^{A}+c_{2}^{B}=\theta_{2}^{A} f_{2}\left(l_{2}^{A}\right)+\theta_{2}^{B} f_{2}\left(l_{2}^{B}\right) .
\end{aligned}
$$

One can show by a simple algebraic exercise that these two conditions, along with the agent's budget constraint, imply that the ex post bond market also clears.

Since the decision problem confronting both the domestic and foreign representative agents is analogous to the problem just considered, equation (10) must be satisfied for both the domestic and foreign consumption levels. The homotheticity assumption on the utility derived from consumption means that the marginal rate of substitution in consumption depends solely on the ratio of the firstand second-period levels. Therefore, this rate of substitution can be expressed by a function $g\left(c_{2} / c_{1}\right)$. This, along with (10), implies that in equilibrium

$$
g\left(c_{2}^{A} / c_{1}^{A}\right)=g\left(c_{2}^{B} / c_{1}^{B}\right)=p
$$

which implies that the ratio of first- and second-period consumption is the same in the two countries. From the goods market equilibrium conditions, this implies that ${ }^{3}$

$$
g\left[\left(y_{2}^{A}+y_{2}^{B}\right) /\left(y_{1}^{A}+y_{1}^{B}\right)\right]=p .
$$

From equation (15), we see that the assumptions about agents' preferences imply that the relative price of secondperiod consumption in terms of first-period consumption depends solely upon the ratio of second- and first-period world output.

In order to understand the model's implications with regard to the response to different levels of the productivity parameters, it is helpful to understand the response of a single country when we do not take account of any interaction effects that would occur through the intertemporal relative price $p$.

\footnotetext{
${ }^{3}$ The fact that $c_{2}^{A} / c_{1}^{A}=c_{2}^{B} / c_{1}^{B}$ implies that there exists an $\alpha$ such that $c_{1}^{A}=\alpha c_{i}^{B}$ for $i=1,2$. This implies that $\left(y_{2}^{A}+y_{2}^{B}\right) /\left(y_{1}^{A}+y_{1}^{B}\right)=\left(c_{2}^{A}+c_{2}^{B}\right) /\left(c_{1}^{A}+c_{1}^{B}\right)=\left[(1+\alpha) c_{1}^{A}\right] /\left[(1+\alpha) c_{2}^{A}\right]$ $=c_{1}^{A} / c_{2}^{A}=c_{2}^{B} / c_{1}^{B}$.
} 
The first effect of a change in a country's own productivity parameter $(\theta)$ is to cause the level of output and the marginal product of labor of the affected project to change. This, in turn, leads to a relative reallocation of labor effort toward the project for which the productivity shock variable has become relatively higher, and the change in the relative labor allocation along with the increase in the project's relative productivity shock variable combine to raise the output of this good and lower the output of the other good. ${ }^{4}$ At the same time, the income effect tends to cause labor effort in both projects to fall. It is ambiguous whether total labor effort rises in response to an increase in one or both of the productivity shock variables. However, because the relative price is unchanged, consumption increases in both periods in such a way as to keep their ratio constant. ${ }^{5}$

The impact of any foreign productivity shock on the domestic agents' choices can only come through the intertemporal price of consumption. An increase in the real world interest rate, $(1 / p)-1$, would have the following substitution effects. Equation (10) implies that $c_{1} / c_{2}$ would fall, while equation (11) implies that $l_{1} / l_{2}$ would rise. Thus, the substitution effects tend to cause the trade balance, which is given by the difference between output and consumption, to increase in the first period and to decrease in the second. This follows naturally from the fact that, under this primitive financial system, the trade balance is equal to saving. What would actually happen to the levels of the agents' choice variables would also depend upon the income effects, which would in turn depend upon whether the agents were net borrowers or lenders in the first period prior to the change in the real interest rate.

I am now ready to undertake a full or general equilibrium analysis of the two-country economy's response to productivity shocks. From equation (11), I get

$$
\theta_{1}^{A} f_{1}\left(l_{1}^{A}\right) / \theta_{2}^{A} f_{2}\left(l_{2}^{A}\right)=\theta_{1}^{B} f_{1}\left(l_{1}^{B}\right) / \theta_{2}^{B} f_{2}\left(l_{2}^{B}\right) .
$$

Equation (16) implies that the international bond market has served to equalize the ratio of marginal products of labor between countries. From this condition, we can also see the impact of productivity shocks upon domestic and foreign output. An increase in $\theta_{1}^{A}$ implies that $l_{1}^{A}$ will rise relative to $l_{2}^{A}$ and also that $l_{1}^{A} / l_{2}^{A}$ will rise relative to $l_{1}^{B} / l_{2}^{B}$. But since this will change the world's output ratio, the real rate of interest will also fall, which will reduce the magnitudes of the above shifts. In addition, the rise in $p$ will cause a reallocation of labor effort in the foreign country, resulting in a fall in $l_{1}^{B} / l_{2}^{B}$. This reallocation of labor effort will be induced via changes in the world interest rate. Similarly, the rise in $p$ will induce a shift in consumption toward the first period.

In equilibrium, the relationship between productivity shocks and the trade balance, which is simply the difference between a country's output and consumption in a particular period, is ambiguous. A change in a country's productivity shock parameters will induce a change in the world's relative price of the second-period consumption good. This change in the relative price will induce both substitution and income effects. The substitution effects induced by the change in the relative price will tend to reduce the magnitude of the change in the trade balance; however, since the ratio of current to future consumption and the ratio of the current to the future marginal productivity of labor are equalized across countries, these priceinduced substitution effects, induced by the change in the relative price of the consumption good, cannot overcome the direct substitution effects. The change in the relative price of the consumption good can also induce income effects if one of the countries is a net lender and the other a net borrower. The substitution and income effects induced by the price change can overcome the direct substitution effects.

The capital market is serving as the only propagation mechanism through which shocks in one country impact upon another. This is due in part to the fact that I have abstracted away from labor, capital, and intermediate goods flows between countries.

\section{A Sophisticated Financial Structure}

A securities market serves two general functions: It allows agents to separate the timing of their consumption and production activities, and it allows risk-sharing. The primitive system of ex post bonds just considered can only fulfill the first of these two functions. It cannot allow for risk-sharing since trading in these bonds occurs only after the resolution of uncertainty, and the payoffs are not statecontingent. I will now consider a model in which the most elaborate possible system of financial contracts can be exchanged prior to the realization of the productivity shocks. This will enable the financial structure I consider here to

\footnotetext{
${ }^{4}$ Removing the assumption that project 1 and 2 labor efforts are perfect substitutes dampens the change in the labor effort ratio, but not the implied direction.

${ }^{5}$ These statements are verified and an explicit expression for determining whether labor effort rises or falls is derived in Cole 1988.
} 
completely fulfill both of the two general functions of a securities market.

Formally, I will now assume that there exists a complete contingent-claims securities market which meets before the productivity shocks are known. By this I mean that for every possible state $s$ (for every possible realization of both the first- and second-period productivity shocks both at home and abroad) there exists an individual security with which one can promise to buy and sell units of both the first- and second-period consumption goods conditional on the state $s$ being realized. Formally, $s$ is defined as a vector which gives the values of the four productivity shocks, and I will denote the set of possible states by $S$. As Arrow (1964) originally observed, this type of elaborate securities market means that agents will be able to treat consumption and output in each state and in each period as a different good with a known price. The price of a unit of the first-period consumption good in state $s$ is $q(s)$, and that of the second-period good is $r(s)$. I will normalize these prices by requiring that

$$
\sum\{q(s)+r(s)\}=1 .
$$

In the previous model, the agents made all of their decisions after all uncertainty was resolved; hence, they only needed to be able to evaluate certain outcomes. Here, however, I will have to define the agents' preferences over uncertain prospects. I will make the standard assumption that agents seek to maximize the expected value of their utility function.

With this financial structure and my assumptions about preferences, the maximization problem of an agent can be written in this way:

$$
\text { choose }\left\{c_{1}(s), c_{2}(s), l_{1}(s), l_{2}(s)\right\}
$$

for all $s$ in $S$ so as to

$$
\operatorname{maximize} \sum_{s}\left\{u\left[c_{1}(s), c_{2}(s)\right]-v\left[l_{1}(s)+l_{2}(s)\right]\right\} h(s)
$$

subject to

$$
\begin{aligned}
& \sum_{s}\left(q(s)\left\{\theta_{1}(s) f_{1}\left[l_{1}(s)\right]-c_{1}(s)\right\}\right. \\
& \left.\quad+r(s)\left\{\theta_{2}(s) f_{2}\left[l_{2}(s)\right]-c_{2}(s)\right\}\right) h(s)=0 .
\end{aligned}
$$

An agent's first-order conditions are

$$
\begin{aligned}
& u_{1}(\cdot)=\lambda q(s) \\
& u_{2}(\cdot)=\lambda r(s)
\end{aligned}
$$

$$
\begin{aligned}
& v^{\prime}(\cdot)=\lambda q(s) \theta_{1}(s) f_{1}^{\prime}(\cdot) \\
& v^{\prime}(\cdot)=\lambda r(s) \theta_{2}(s) f_{2}^{\prime}(\cdot) .
\end{aligned}
$$

The assumption that $\theta^{A}$ and $\theta^{B}$ are independently and identically distributed, along with the assumption of identical preferences and production functions, implies that the domestic and foreign agents are ex ante identical. This, in turn, implies that $\lambda^{A}=\lambda^{B}$, or that the agents' expected marginal utilities of income are equal. Because of the separability of consumption and labor effort in the agents' preferences, this implies that

$$
u_{1}\left[c_{1}^{A}(s)\right]=u_{1}\left[c_{1}^{B}(s)\right]
$$

and

$$
u_{2}\left[c_{2}^{A}(s)\right]=u_{2}\left[c_{2}^{B}(s)\right]
$$

for all $s$ in $S$, since the marginal utility of consumption depends solely on the level of consumption. Or, in words, the implication is that for any given state of the world, the consumptions of the foreign and domestic agents are identical. This is in contrast to the model with only ex post securities, where only the ratios of first- and second-period consumption were equalized, not their levels. With Arrow securities, the agents choose to completely insure their consumption against individual-specific risk; however, their consumption is still subject to aggregate risk.

Once again, an agent's first-order conditions for labor effort, (23) and (24), imply that the ratio of marginal products is equalized across countries, but labor effort itself is not equalized. This is because there does not exist a market in productivity shocks; that is, one's $\theta$ is a nontraded input, and laborers are immobile across countries. Unlike the case of consumption, agents are not completely insuring their labor effort against individual-specific risks. This stems from the fact that while the price of consumption is the same in both countries in any given state of the world, the price of leisure is not. The agent with the higher productivity parameter works harder, but consumes no more than the agent with the lower productivity parameter. In fact, the impact of an increase in one agent's productivity parameter on the current project's effort level of the other agent is negative. For example, if the project 1 productivity parameter of agent $A$ increases, then the project 1 effort level of the other agent, agent $B$, actually declines, as does $B$ 's total effort level, though $B$ 's effort level devoted to producing future output increases. For this 
reason, labor effort across countries will actually tend to be negatively correlated in the model.

While this negative correlation also arises under the first financial structure that I considered, it is more negative here. This is because with complete markets, the transfer from agent $A$ to agent $B$ of first-period consumption lowers $B$ 's marginal utility of consumption in that period, which lowers $l_{1}^{B}$ while inducing a rise in $l_{2}^{B}$. The equalization of the per-period marginal utilities of consumption implies that agent $A$ shares equally in terms of consumption in the net increase in second-period output induced by the reallocation of effort.

While an agent would prefer a higher level of the productivity shocks for the world as a whole, ex post the agent would prefer that the other agent's productivity parameters be higher than his or her own. Under the previous financial structure, which is composed of ex post securities, an agent prefers to have his or her own productivity parameters be higher than the other agent's. Thus, the change in the financial structure has resulted in the sort of ex post preference reversal first noted by Stockman and Dellas (1986) within the context of a model of anticipated tariffs.

Previously, the only channel for shocks in one country to impact upon another was the bond market and the intertemporal relative price of consumption. The existence of an Arrow securities market introduces a direct dependence between one agent's choice variables and the other agent's productivity shocks which does not depend upon the intertemporal relative price of consumption. This direct dependence can potentially arise within any financial structure which allows agents to trade contingent assets prior to the resolution of uncertainty. Asset returns are acting as an important transmission mechanism because the agents contract in the ex ante securities market to receive state-contingent transfers. The magnitude of the net transfer that one agent receives from the other agent is positively related to the discrepancy between the productivity parameters of the first agent and those of the second.

The change in the financial structure has altered the relative magnitudes of the fluctuations in consumption and output. Variations in an agent's productivity parameters induce both income and substitution effects. The existence of Arrow securities reduces the magnitude of the income effect associated with changes in an agent's own productivity parameters. In states in which an agent's productivity parameter for a period is relatively high (or low), the agent has committed to deliver a larger (or smaller) num- ber of that period's consumption units to the other agent. The agents have used the Arrow securities to enter into an implicit pooling agreement, and as a result, consumption in each of the two countries is less variable. The strong result that the agents in the two countries equalize their consumption in each state is dependent upon the assumption that the agents' preferences are separable in consumption and labor effort and that their ex ante wealth is equal. However, in any model in which agents desire to smooth their consumption, one will find the variance of consumption decreasing and the covariance between domestic and foreign consumption increasing as financial markets become more complete.

The covariance between an agent's consumption and the agent's productivity shock variables has also been reduced. An agent's ex post wealth is now less positively related to the agent's own productivity parameters. This reduces the magnitude of the income effects which tended to cause the agent to decrease labor effort when productivity parameters were high and increase that effort when they were low, which in turn increases the variability of the agent's output. In addition, there has been a reduction in the tendency for output and consumption to move together. This reduction occurs because one agent's obligations to the other agent are positively related to the first agent's productivity shock variables.

The impact of the change in the financial structure upon the variability of an agent's labor effort and the trade balance is ambiguous. The direction of the change in the variability of labor effort will depend upon whether the substitution effect dominated movements in labor effort under the previous financial structure. If the substitution effect dominated the income effect, as seems to be implied by the empirical observation that labor effort is procyclical, then the change will cause labor effort to become more variable. To the extent that the income effect dominated the substitution effect, the change in financial structure will tend to reduce the variability of labor effort. The variance of the trade balance $T B$ can be written as

$$
\operatorname{var}(T B)=\operatorname{var}(y-c)=\operatorname{var}(y)+\operatorname{var}(c)-2 \operatorname{cov}(y, c) .
$$

As was pointed out above, the change in the financial structure has raised the variance of $y$ and lowered the covariance between $y$ and $c$, which tends to raise the variance of the trade balance. However, the fall in the variance of consumption tends to lower it.

It is worth noting in passing that the trade balance is no 
longer equal to an agent's first-period saving since it does not take into account the ex post transfers induced by the Arrow securities. With the first financial structure I considered, since the trade balance was equal to saving, the present value of the trade balance (the sum of the firstperiod balance and the second-period balance weighted by its relative price) was always equal to zero. That need no longer be true here. In fact, it is quite possible here for a country to have a trade deficit (or surplus) in both periods if its productivity shocks are low (or high) relative to those abroad. Thus, the more sophisticated financial structure would seem to allow for more persistent deficits in the trade balance.

Also, with the first financial structure considered, and under the assumption that there were no initial debts, the trade balance was equal to the current account, which is a measure of the net accumulation of claims (in the form of credit extended or direct investment abroad) on the rest on the world. There is a natural sense in which the current account is equal to zero with complete markets. This is because in the ex ante securities market, claims of equal value are traded, and after that there is no further asset trade and, hence, no net accumulation or decumulation.

\section{Related Research}

In light of the discussion thus far, two natural concerns arise. One is the extent to which the results derived are robust: if I compare two financial structures which can somehow be ranked in terms of their sophistication, will similar qualitative conclusions emerge? The other concern is the extent to which the predicted changes are quantitatively significant and, hence, should be taken seriously.

In order to address the first concern, I need some sort of measure in terms of completeness of financial structures if I am to rank them. This is a difficult issue. However, I can restrict myself to more obvious comparisons. If a given financial structure allows all of the trades that another structure does and some that it does not, then I can safely say that the given structure is more complete. In Cole 1988, an intermediate comparison is made in which production is undertaken by firms. The firms hire labor in competitive labor markets. Equity claims on the firm's profits alone are traded in the ex ante securities market. The results are consistent with those I have derived here. However, this is again a fairly stark comparison, and there is nothing to suggest that small changes in a given financial structure could not lead to perverse results. (See Hart 1975 in this regard.) Clearly, then, the re- sults that I have derived must be viewed with some degree of caution.

With regard to the second concern, there are really two questions: To what extent does this matter in welfare terms? And to what extent are changes in financial structure likely to lead to different outcomes? The reason for the distinction is that different financial structures could result in very different outcomes, for example, in terms of agents' consumption or labor effort choices, without there being much difference in their equilibrium welfare levels.

The first of these questions has been addressed in a series of papers beginning with that of Cole and Obstfeld (1991), who argue that at least for developed countries in which output fluctuations tend to be small and outputs fairly highly correlated, the welfare gains or losses associated with greater international risk-sharing are likely to be small. Obstfeld (1991) and Van Wincoop (1991) have explored the effects of alternative specifications of preferences - and Obstfeld, the stochastic process generating output - on the cost of consumption variability. While alternative preferences which raise the costs associated with consumption variability, like allowing for habit persistence, can make the welfare consequences of consumption fluctuations larger, it seems unlikely that these specifications are generally consistent with the data. For example, preferences which place a high premium on consumption-smoothing would almost certainly generate a too smooth consumption series and too variable investment series within a standard real business cycle model since standard preference specifications are consistent with the data in this regard. Obstfeld's results on the cost of consumption variability across countries suggest that this cost remains fairly small for developed countries, where output fluctuations tend to be small, but may be larger for underdeveloped countries.

In order to deal with the second question, about different financial structures leading to different outcomes, one would need to consider a plausibly parameterized quantitative general equilibrium model. This was precisely the goal of Baxter and Crucini (1992), who have undertaken a comparison similar to mine. They do their analysis within a standard real business cycle model which has been expanded to consider two countries. Qualitatively, they find that in their model the effects of shifting between two financial structures which are analogous to the ones I have considered are essentially the same as the results implied by the model presented here for the limited number of statistics that they report. Specifically, the cross-country cor- 
relation of consumption increases, while those of output and labor effort decline.

Unfortunately, Baxter and Crucini's (1992) quantitative answers with regard to magnitudes of the effects of changing financial structures turn out to depend crucially on the fine details of the stochastic process governing the fluctuations in the productivity parameters, about which there is a great deal of uncertainty. If the productivity process is trend stationary, so shocks are persistent but not permanent, then they find, as did earlier related work by Backus, Kehoe, and Kydland (1992), that the structure of financial markets doesn't matter much. However, if the productivity process is difference stationary, so that all shocks are permanent, then the structure of financial markets appears to matter a great deal. Under the assumption that the productivity process is difference stationary, Baxter and Crucini (1992) generally confirm the results of our analytic model.

One of the surprises in their results is that increasing the sophistication of international financial markets actually switches the sign of the cross-country correlation of consumption from negative to positive, while the crosscountry correlation of output goes from positive to negative. In addition, and as was noted in the discussion of Arrow securities, a complete market structure tends to induce a negative cross-country correlation of labor effort. Baxter and Crucini (1992) not only confirm that the correlation becomes more negative as financial markets become more complete, but they also find that the correlation is negative in all of the cases that they consider. This finding is substantially at variance with the generally positive cross-country correlations of labor effort that we see in the data.

\section{Concluding Comments}

The research program that aims to examine the impact of changes in international financial structure on agents' decisions and, hence, on macroeconomic aggregates is still at a quite preliminary stage, and there is ample scope for future research. The simple model presented here is attractive in that it seems capable of generating some fairly strong empirical predictions. However, many of the fundamental issues still remain to be resolved.

Foremost is the question, Are changes in financial structure of the magnitude seen in the real world, as opposed to the stark contrasts considered in this article, likely to have much effect in terms of either welfare or actions? The answer to this question may turn on a number of factors. As was noted, one of these may well be the nature of the stochastic process generating productivity shocks.

There are also other issues which I have not yet mentioned. For example, an unexamined question is, How sensitive are my results to the assumed domestic financial structure? Are there greater gains from international risksharing when domestic financial markets are more primitive? Another example of a potentially important question for future research is, What is the role of international financial markets in risk-sharing and in ensuring an efficient allocation of capital across countries? ${ }^{6}$ In both cases it may turn out to be the case that these markets have more to contribute when countries are very dissimilar, such as developed and undeveloped or fast and slow growing, than when they are very similar. ${ }^{6}$ Obstfeld (1992) generates a model in which the growth rate itself may be affected
by the degree of financial intermediation. 


\section{References}

Arrow, K. J. 1964. The role of securities in the optimal allocation of risk-bearing. $R e$ view of Economic Studies 31 (April): 91-96.

Backus, David K.; Kehoe, Patrick J.; and Kydland, Finn E. 1992. International real business cycles. Journal of Political Economy 100 (August): 745-75.

Forthcoming. International business cycles: Theory and evidence. In Frontiers of business cycle research, ed. Thomas F. Cooley. Princeton, N.J.: Princeton University Press.

Baxter, Marianne, and Crucini, Mario J. 1992. Business cycles and the asset structure of foreign trade. Discussion Paper 59. Institute for Empirical Macroeconomics (Federal Reserve Bank of Minneapolis).

Cole, Harold. 1988. Financial structure and international trade. International Economic Review 29 (May): 237-59.

Cole, Harold L., and Obstfeld, Maurice. 1991. Commodity trade and international risk sharing: How much do financial markets matter? Journal of Monetary Economics 28 (August): 3-24.

French, Kenneth R., and Poterba, James M. 1991. Investor diversification and intemational equity markets. American Economic Review 81 (May): 222-26.

Hart, Oliver D. 1975. On the sptimality of equilibrium when the market structure is incomplete. Journal of Economic Theory 11 (December): 418-43.

Helpman, Elhanan, and Razin, Assaf. 1978. A theory of international trade under uncertainty. New York: Academic Press.
Jones, Ronald W., and Neary, J. Peter. 1984. The positive theory of international trade. In Handbook of international economics, ed. Ronald W. Jones and Peter B. Kenen, Vol. 1. Amsterdam: North-Holland.

Kydland, Finn E., and Prescott, Edward C. 1982. Time to build and aggregate fluctuations. Econometrica 50 (November): 1345-70.

Obstfeld, Maurice. 1991. On the aggregate cost of consumption variability. Manuscript. University of California, Berkeley.

1992. Risk-taking, global diversification, and growth. Discussion Paper 61. Institute for Empirical Macroeconomics (Federal Reserve Bank of Minneapolis).

Prescott, Edward C. 1986. Theory ahead of business cycle measurement. Federal Reserve Bank of Minneapolis Quarterly Review 10 (Fall): 9-22. Also, 1986 in Real business cycles, real exchange rates and actual policies, ed. Karl Brunner and Allan H. Meltzer. Carnegie-Rochester Conference Series on Public Policy 25 (Autumn): 11-44. Amsterdam: North-Holland.

Stockman, Alan C., and Dellas, Harris. 1986. Asset markets, tariffs, and political risk. Journal of International Economics 21 (November): 199-213.

Svensson, Lars E. O. 1988. Trade in risky assets. American Economic Review 78 (June): 375-94.

Tesar, Linda L., and Werner, Ingrid M. 1992. Home bias and the globalization of securities markets. Working Paper 4218. National Bureau of Economic Research.

Van Wincoop, Eric. 1991. Welfare gains from international risk sharing. Manuscript. Boston University. 